\title{
Evidence or Experience: That is the Question
}

\author{
Farzam Gorouhi $\cdot$ Howard Maibach
}

Published online: 8 July 2014

(c) Springer International Publishing Switzerland 2014

This special issue does not intend to provide an explicit overview of all available evidence in the various fields of dermatology. Instead, it attempts to provide an efficient overview of the latest available evidence on selected topics. All dermatologists with different backgrounds need a periodic update on the available evidence and may not have the time to review each topic comprehensively. We all know that performing a comprehensive systematic review, such as a Cochrane review, entails many details, and reading such a review is not necessarily time efficient for busy practitioners. Thus, we emphasize the usefulness of the summary tables in this issue to present results of randomized trials and, more importantly, to provide general recommendations for each treatment modality. Practicing dermatologists may not be able to dedicate sufficient time to reading and reviewing the updated evidence. Therefore, it may be more useful for them to study summarized, updated, evidence-based reviews. The intention of this issue was to fulfill this need.

We have often been asked why we believe in an evidence-based philosophy in the age of personalized medicine. The critical point that is frequently missed is that "Evidence-based medicine is not 'cookbook' medicine" [1]. You need to know the current evidence. You may need

F. Gorouhi $(\bowtie)$

Department of Dermatology, University of California, Davis, 3301 C St. Suite 1400, Sacramento, CA 95816-3367, USA e-mail: farzam.gorouhi@ucdmc.ucdavis.edu

H. Maibach

Department of Dermatology, University of California, San Francisco, 90 Medical Center Way, Surge 110, San Francisco, CA 941430-0989, USA

e-mail: maibachh@derm.ucsf.edu to know the quality of the studies as well as the strength of recommendations for therapeutic modalities; but you recommend it only after considering your experience, judgment, and common sense. Here, we would like to underscore some common misperceptions about evidencebased medicine. For example, underlying diseases are seldom discussed in evidence-based guidelines; therefore, it is the physician's responsibility to customize treatment strategies for patients based on all the aspects, including but not limited to concurrent diseases, drug history, age, gender, ethnicity, social history, and, most importantly, patient preference [2]. Moreover, evidence-based medicine has its limitations. For instance, since therapeutic systematic reviews rely primarily on phase II and III randomized controlled trials, they may underestimate infrequent adverse events. Phase IV post-marketing surveillance studies can help detect these rare occurrences; however, they are often not available. Looking for all adverse effects may be more beneficial to patients, especially if they have genetic or environmental predisposing factors. Let us give you a rare clinical scenario: If a male patient has a paternal or maternal family history of $B R C A$ gene mutation, his dermatologist should be more cautious in prescribing a lifelong finasteride treatment for his androgenetic alopecia and should monitor the patient for possible cancer-related signs or symptoms in the breast or other organs more often than in a patient with no relevant underlying risk factors. Such a clinical decision is not in any evidence-based guideline but is congruent with its principles. Additionally, anecdotal experience may be helpful, specifically if the literature lacks an appropriate systematic review. Unfortunately, this is commonly seen in dermatology. However, it is important to understand that even in the areas with no existing high-level evidence, the evidence-based approach is considered gold standard. 
The following topics are discussed in this issue: atopic dermatitis [3], systemic therapies for psoriasis [4], mucosal lichen planus [5], basal cell carcinoma [6], androgenetic alopecia [7], hirsutism [8], diabetic foot ulcer [9], and alopecia areata [10].

We would like to sincerely thank all of the legendary experts who have dedicated their time and efforts to such extraordinary reviews. We hope this will be a reliable resource for all dermatologists to stimulate their minds to think, interpret, and practice in a systematic way.

Acknowledgments No sources of funding were used to prepare this editorial. The authors have no conflicts of interest that are directly relevant to the content of this editorial.

\section{References}

1. Sackett DL, Rosenberg WM, Gray JA, Haynes RB, Richardson WS. Evidence based medicine: what it is and what it isn't. BMJ. 1996;312(7023):71-2.
2. Maibach HI, Gorouhi F. Evidence based dermatology. Chelton (CT); People's Medical Publishing House; 2011.

3. Silverberg JI. Atopic dermatitis: an evidence-based treatment update. Am J Clin Dermatol. 2014;. doi:10.1007/s40257-014-0062-z.

4. Sandoval LF, Pierce A, Feldman SR. Systemic therapies for psoriasis: an evidence-based update. Am J Clin Dermatol. 2014; doi:10.1007/s40257-014-0064-x.

5. Davari P, Hsiao HH, Fazel N. Mucosal lichen planus: an evidence-based treatment update. Am J Clin Dermatol. 2014; doi:10.1007/s40257-014-0068-6.

6. Clark CM, Furniss M, Mackay-Wiggan JM. Basal cell carcinoma: an evidence-based treatment update. Am J Clin Dermatol. 2014; doi:10.1007/s40257-014-0070-z.

7. Varothai S, Bergfeld WF. Androgenetic alopecia: an evidencebased treatment update. Am J Clin Dermatol. 2014;. doi:10.1007/ s40257-014-0077-5.

8. Somani N, Turvy D. Hirsutism: an evidence-based treatment update. Am J Clin Dermatol. 2014;. doi:10.1007/s40257-014-0078-4.

9. Braun LR, Fisk WA, Lev-Tov H, Kirsner RS, Isseroff RR. Diabetic foot ulcer: an evidence-based treatment update. Am J Clin Dermatol. 2014. doi:10.1007/s40257-014-0081-9.

10. Hordinsky M, Donati A. Alopecia areata: an evidence-based treatment update. Am J Clin Dermatol. 2014. doi:10.1007/ s40257-014-0086-4. 